\title{
High-Level Production of High-Purity Human and Murine Recombinant Prion Proteins Functionally Compatible to In Vitro Seeding Assay ${ }^{\mathbb{S}}$
}

\author{
Hae-Gwang Hwang ${ }^{1 \dagger}$, Dae-Hwan Kim ${ }^{2,3 \dagger}$, Jeongmin Lee ${ }^{4}$, Youngwon Mo $^{2}$, Se-Hoon Lee ${ }^{1}$, Yongjin Lee, \\ Jae Wook Hyeon ${ }^{4}$, Sol Moe Lee, ${ }^{4}$ Yong-Pil Cheon ${ }^{5}$, Eun-Kyoung Choi ${ }^{6}$, Su Yeon Kim${ }^{4}$, Yeong Seon Lee, \\ Young-Jin Son ${ }^{1 *}$, and Chongsuk Ryou ${ }^{2 *}$ \\ ${ }^{1}$ Department of Pharmacy, Sunchon National University, Suncheon 57922, Republic of Korea
${ }^{2}$ Department of Pharmacy and Institute of Pharmaceutical Science E Technology, Hanyang University, Ansan
${ }^{3}$ School of Undergraduate Studies, College of Transdisciplinary Studies, Daegu Gyeongbuk Institute of Scier
42988, Republic of Korea
${ }^{4}$ Division of Zoonoses, Center for Immunology and Pathology, National Institute of Health, Korea Center
Prevention, Cheongju 28159, Republic of Korea
${ }^{5}$ School of Biological Sciences and Chemistry, Sungshin Women's University, Seoul 02844, Republic of Korea
${ }^{6}$ Ilsong Institute of Life Science, Hallym University, Anyang 24252, Republic of Korea
}

Received: May 29, 2018

Revised: July 10, 2018

Accepted: August 27, 2018

First published online

September 3, 2018

${ }^{*}$ Corresponding authors

C.R.

Phone: +82-31-400-5811;

Fax: +82-31-400-5958;

E-mail: cryou2@hanyang.ac.kr

Y.-J.S.

Phone: +82-61-750-3755;

Fax: +82-61-750-3708;

E-mail: sony@sunchon.ac.kr

${ }^{\dagger}$ These authors contributed equally to this work.

S upplementary data for this paper are available on-line only at http://jmb.or.kr.

pISSN 1017-7825, eISSN 1738-8872

\begin{abstract}
Recombinant (rec) prion protein (PrP) is an extremely useful resource for studying protein misfolding and subsequent protein aggregation events. Here, we report mass production of high-purity rec-polypeptide encoding the C-terminal globular domain of PrP; (90-230) for human and (89-231) for murine PrP. These proteins were expressed as His-tagged fusion proteins in E. coli cultured by a high cell-density aerobic fermentation method. RecPrPs recovered from inclusion bodies were slowly refolded under reducing conditions. Purification was performed by a sequence of metal-affinity, cation-exchange, and reverse-phase chromatography. The current procedure yielded several dozens of milligrams of recPrP per liter with $>95 \%$ purity. The purified recPrPs predominantly adopted an $\alpha$-helix-rich conformation and were functionally sufficient as substrates to measure the seeding activity of human and animal prions. Establishment of a procedure for high-level production of highpurity recPrP supports the advancement of in vitro investigations of PrP including diagnosis for prion diseases.
\end{abstract}

Keywords: Expression, high cell-density culture, recombinant prion protein, purification, seeding activity

Copyright(C) 2018 by

The Korean Society for Microbiology and Biotechnology

\section{Introduction}

$\operatorname{PrP}^{\mathrm{C}}$ and $\operatorname{PrP}^{\mathrm{Sc}}$ are two different conformational isoforms of $\operatorname{PrP}$ [1]. $\operatorname{PrP}^{\mathrm{C}}$ is a normal cellular protein that is abundantly expressed in neurons, while $\operatorname{PrP}^{\mathrm{Sc}}$ is an abnormal pathogenic protein that causes progressive neurodegenerative disorders, such as scrapie in sheep, bovine spongiform encephalopathy in cattle, and CJD in humans [1]. By autocatalytic conformational conversion, the $\alpha$-helix-rich $\operatorname{PrP}^{C}$ molecule undergoes misfolding and is transformed into the $\beta$-sheet-rich $\operatorname{PrP}^{S c}$ molecule [2]. In this biochemical process, $\operatorname{PrP}^{S c}$ functions as a template for $\operatorname{PrP}^{\mathrm{C}}$, resulting in nascent $\mathrm{PrP}^{\mathrm{Sc}}$ generation [3]. Because misfolded $\mathrm{PrP}^{\mathrm{Sc}}$ is hydrophobic, it can aggregate in a variety of forms, 
such as small amyloidogenic oligomers, unstructured oligomers, amyloids, filaments, protofibrils, and fibrils [4]. These $\operatorname{PrP}^{\mathrm{Sc}}$ aggregates constitute prion particles that exhibit infectivity [5].

Because the molecular events involved in autocatalytic $\operatorname{PrP}^{\mathrm{Sc}}$ generation and aggregation of $\operatorname{PrP}^{\mathrm{Sc}}$ molecules confer propagation of prion infectivity, production of prion infectivity de novo is the ultimate proof of the protein-only hypothesis in prion biology [6]. Experiments to evaluate the infectivity of misfolded protein aggregates have been performed with defined materials, such as recPrP expressed in bacteria [6, 7]. Furthermore, recPrP has been used as a source of antigens to raise anti-PrP antibodies [8-14]. Highly purified recPrP itself is essential to resolve the three-dimensional structure of $\mathrm{PrP}$ in various conformations [15-21]. Demand for recPrP has increased as it has become the major material for in vitro PrP aggregation assays, such as the PrP amyloid formation assay (PAFA) or real-time quaking assay (RT-QuIC), which are used to detect the "seeding activity" of prions [22-24]. These assays are powerful tools for prion diagnosis as they measure acceleration of PrP amyloid formation initiated by misfolded PrP conformers as seeds.

A number of studies have described expression and purification of recPrP in E. coli, Pichia, and cultured insect cells [8, 25-35]. Although bacterially expressed recPrP lacks posttranslational modifications, the E. coli system is most widely used to produce recPrP. Because $\operatorname{PrP}^{C}$ is a membrane protein tethered to the plasma membrane via a glycosylphosphatidylinositol anchor and associated with lipid- and/or cholesterol-rich domains of the plasma membrane [36, 37], production of $\mathrm{recPrP}$ as a soluble recombinant protein is difficult. Thus, $\mathrm{recPrP}$ is usually expressed as an insoluble protein in inclusion bodies within the bacterial cells and then solubilized for purification $[8,26,27,34,35$, 38]. However, preparation of purified recPrP is still a difficult task because of the intrinsic characteristics of PrP. This protein is notorious for its non-specific interactions with proteins and other biological macromolecules as well as the surfaces of nonbiological materials, such as steel and plastic [39-42]. Affinity tagging of recPrP makes purification easier. Usually, recPrP is expressed as a protein with a fusion tag and is purified by single-step affinity chromatography [8, $25-27,33,34,43,44]$, although recPrP can be expressed and purified without a tag via multiple chromatography steps [35]. In addition, $\operatorname{PrP}$ tends to be partially precipitated during refolding performed after purification [35]. Although slow refolding of diluted recPrP in acidic $\mathrm{pH}$ may minimize the appearance of insoluble aggregates [45], the loss of a considerable amount of recPrP results in a low concentration of refolded protein [34, 35, 46-48]. Thus, an additional step to concentrate recPrP is frequently needed.

Nonetheless, some studies have reported the large-scale preparation of recPrP $[34,35]$, while others have described the production of highly pure recPrP [27]. However, it is still difficult to obtain a large quantity of highly pure recPrP using existing expression and purification procedures. Problems associated with the aforementioned intrinsic properties of recPrP, loss of expressed protein during purification, refolding, and concentration processes, and the limitations of low density cell cultures, leading to a small mass of starting material, have hindered the production of concentrated, high-purity recPrP.

To address the problems associated with production of a large quantity of highly pure recPrP, we report the massproduction of high-purity His-tagged human (h) and mouse (m) recPrP spanning the C-terminal core region (amino acids 90-230 for human and 89-231 for mouse; Fig. S1) based on the combined approach of high cell-density aerobic fermentation and a series of chromatography steps for purification. Furthermore, we provide evidence that recPrP prepared by the present methodology is suitable as a substrate to measure the seeding activity of prions.

\section{Materials and Methods}

\section{Cloning of PrP Genes in Bacterial Expression Vectors}

For expression of His-tagged [(His) $\left.6_{6}^{-}\right] \mathrm{hPrP}(90-230)$ and $\mathrm{mPrP}(89-$ 231), DNA fragments encoding $h \operatorname{PrP}(90-230)$ and $\mathrm{mPrP}(89-231)$ were cloned into the bacterial expression vector, pET100/DTOPO (Invitrogen, USA), as described previously [23]. Human and mouse PrP DNA fragments were obtained by PCR, using the complete DNA sequences for the PrP genes cloned in the pSP72 cloning vector as templates. PCR primers were as follows: for hPrP(90-230) gene cloning, forward primer - 5' CTA CGA TCC TCT CTG GTA ATA 3'; reverse primer - 5' TCA TCC CAC TAT CAG GAA GAT GAG 3': for $\mathrm{mPrP}(89-231)$ gene cloning, forward primer - 5' CAC CGG CCA AGG GGG TAC CCA 3'; reverse primer - 5' TCA GCT GGA TCT TCT CCC GTC GTA 3'. PCR was performed under the following conditions: 1 cycle of $95^{\circ} \mathrm{C}$ for $10 \mathrm{~min}, 35 \mathrm{cycles}$ of $95^{\circ} \mathrm{C}$ for $30 \mathrm{sec} / 58^{\circ} \mathrm{C}$ for $30 \mathrm{sec} / 72^{\circ} \mathrm{C}$ for $1 \mathrm{~min}$, and $1 \mathrm{cycle}$ of $72^{\circ} \mathrm{C}$ for $7 \mathrm{~min}$. The resultant recombinant plasmids were used to transform E. coli BL21 Star(DE3) (Invitrogen). This was accomplished according to the manufacturer's instruction and a modified protocol described previously [23]. Recombinant plasmids harboring PrP DNA fragments were sequenced to 
confirm cloning of corresponding gene fragments with no unintended mutations (Cosmo Genetech, Korea).

\section{Expression of (His) ${ }_{6}$-hPrP(90-230) and (His) ${ }_{6}-\mathrm{mPrP}(89-231)$ Using High Cell-Density Aerobic Fermentation}

The overall scheme for expression and purification is depicted in Fig. S2. E. coli BL21 Star(DE3) cells transformed with recombinant plasmids for (His) ${ }_{6}-\mathrm{hPrP}(90-230)$ and (His) ${ }_{6}-\mathrm{mPrP}(89-231)$ were cultured in $25 \mathrm{ml} \mathrm{LB}$ medium supplemented with $50 \mu \mathrm{g} / \mathrm{ml}$ ampicillin (Sigma-Aldrich, USA) at $37^{\circ} \mathrm{C}$ as seed cultures. When the $\mathrm{OD}_{600}$ of the cultured cell broth was 0.7 , the seed culture was used to inoculate $1 \mathrm{~L}$ of fermentation medium (tryptone $10 \mathrm{~g} / \mathrm{l}$, yeast extract $5 \mathrm{~g} / \mathrm{l}, \mathrm{NaCl} 5 \mathrm{~g} / \mathrm{l}, \mathrm{K}_{2} \mathrm{HPO}_{4} 5 \mathrm{~g} / \mathrm{l}$ ) in an aerated $2.5 \mathrm{~L}$ fermentor (Sartorius Stedim Biotech, France). After 15-16 h of growth at $25^{\circ} \mathrm{C}$, the temperature was raised to $30^{\circ} \mathrm{C}$ to induce expression of (His) $)_{6} \mathrm{hPrP}(90-230)$ and to $37^{\circ} \mathrm{C}$ to induce expression of (His) $)_{6}-\mathrm{mPrP}(89-231)$. Induction was performed by addition of IPTG (Invitrogen) to a final concentration of $1 \mathrm{mM}$ when the $\mathrm{OD}_{600}$ was over 10. During aerobic fermentation (hereafter, fermentation), glucose and $\mathrm{NH}_{4} \mathrm{OH}$ were used as nutrients and $\mathrm{pO}_{2}$ was kept to $30 \%$ to maintain the $\mathrm{pH}$ at 6.9 .

Cell Lysis and Washing of Inclusion Bodies Containing (His) ${ }_{6}^{-}$ hPrP(90-230) and (His) ${ }_{6}$-mPrP(89-231)

Cells were harvested by centrifugation at $12,000 \times g$ at $4^{\circ} \mathrm{C}$ for $30 \mathrm{~min}$. Cell pellets were resuspended in $20 \mathrm{ml}$ of resuspension buffer (10\% sucrose, $0.1 \mathrm{M}$ Tris, $50 \mathrm{mM}$ ethylenediaminetetraacetic acid (EDTA), $0.2 \mathrm{M} \mathrm{NaCl}, \mathrm{pH} 7.9$ ) per $1 \mathrm{~g}$ of cell weight. Resuspended cells were disrupted using a homogenizer (SPX FLOW, USA) and centrifuged at $12,000 \times g$ at $4^{\circ} \mathrm{C}$ for $30 \mathrm{~min}$. The supernatant was discarded and the pellet, comprising inclusion bodies containing (His) ${ }_{6}$-hPrP(90-230) or (His) ${ }_{6}-\mathrm{mPrP}(89-231)$, was collected. The pellet was washed with $30 \mathrm{ml}$ of inclusion body washing buffer (20 mM Tris, 1 mM EDTA, 0.02\% lysozyme, 1\% Triton X-100, 0.5 $\mathrm{M}$ urea) per $1 \mathrm{~g}$ of pellet for $2 \mathrm{~h}$. The inclusion body wash was repeated once again and the final wash was completed with deionized water in the same manner.

\section{Direct Refolding of Recombinant (His) ${ }_{6}-\mathrm{hPrP}(90-230)$ and (His) ${ }_{6}-$ mPrP(89-231)}

Washed inclusion bodies were dissolved in solubilization buffer (8 M urea, $10 \mathrm{mM}$ glycine, $\mathrm{pH}$ 10.6). The inclusion body solution was diluted with refolding buffer $(0.6 \mathrm{M}$ urea, $10 \mathrm{mM}$ glycine, $\mathrm{pH}$ 10.6) to a final protein concentration of $0.5 \mathrm{mg} / \mathrm{ml}$ and incubated at $4^{\circ} \mathrm{C}$ for $16 \mathrm{~h}$ with $0.1 \mathrm{mM} \beta$-mercaptoethanol. Refolded recPrP solution was adjusted to $20 \mathrm{mM}$ Tris, $0.5 \mathrm{M} \mathrm{NaCl}, 5 \%$ glycerol.

\section{IMAC}

IMAC was performed with refolded recPrPs using a HisPrep FF 16/10 column (GE Healthcare Bio-Sciences, USA). The protein solution was loaded at a flow rate of $3 \mathrm{ml} / \mathrm{min}$ on a $20 \mathrm{ml}$ HisPrep FF 16/10 column equilibrated with five CVs of binding buffer (50 mM Tris, $0.5 \mathrm{M} \mathrm{NaCl}, 5 \%$ glycerol, $\mathrm{pH} 8.0$ ) at a flow rate of
$5 \mathrm{ml} / \mathrm{min}$. The column was washed with five CVs of washing buffer ( $20 \mathrm{mM}$ Tris, $0.5 \mathrm{M} \mathrm{NaCl}, 5 \%$ glycerol, $100 \mathrm{mM}$ imidazole, $\mathrm{pH} 8.0$ ) at a flow rate of $5 \mathrm{ml} / \mathrm{min}$. Bound proteins were eluted with two CVs of elution buffer $(20 \mathrm{mM}$ Tris, $0.5 \mathrm{M} \mathrm{NaCl}, 5 \%$ glycerol, $1 \mathrm{M}$ imidazole, $\mathrm{pH} 8.0$ ) at a flow rate of $5 \mathrm{ml} / \mathrm{min}$. The eluent was collected in $5 \mathrm{ml}$ aliquots in fraction tubes.

\section{Cation Exchange Chromatography}

IMAC eluate fractions containing recombinant (His) $)_{6}-\mathrm{hPrP}(90-$ $230)$ and (His) ${ }_{6}-\mathrm{mPrP}(89-231)$ were pooled and subjected to cation exchange chromatography using the AKTA Avant system (GE Healthcare Bio-Sciences) equipped with a $20 \mathrm{ml}$ Sp Sepharose fast flow resin (GE Healthcare Bio-Sciences) in an XK 16 column (GE Healthcare Bio-Sciences). The pooled samples were desalted with equilibrium buffer (7 M urea, $0.25 \mathrm{M}$ acetic acid, $\mathrm{pH}$ 2.5) using Stirred Ultrafiltration Cells containing a $3 \mathrm{kDa}$ ultrafiltration membrane (Millipore, USA). The column was equilibrated with $10 \mathrm{CVs}$ of equilibrium buffer at a flow rate of $3 \mathrm{ml} / \mathrm{min}$, loaded with the pooled sample at a flow rate of $1 \mathrm{ml} / \mathrm{min}$, and washed with $10 \mathrm{CVs}$ of equilibrium buffer at a flow rate of $3 \mathrm{ml} / \mathrm{min}$. Then, bound proteins were eluted with $20 \mathrm{CVs}$ of equilibrium and elution buffers ( $7 \mathrm{M}$ urea, $0.25 \mathrm{M}$ acetic acid, $1 \mathrm{M} \mathrm{NaCl}, \mathrm{pH} 2.5$ ) by application of a linear gradient $(0-1 \mathrm{M} \mathrm{NaCl})$ at a flow rate of $3 \mathrm{ml} / \mathrm{min}$. During this process, the solution was monitored at $280 \mathrm{~nm}$ and each peak was collected in fraction tubes.

\section{Prep-HPLC}

Cation exchange chromatography fractions were further purified by reverse phase chromatography. For this purification step, Prep-HPLC was carried out on an Agilent 1200 system (Agilent Technologies, USA) equipped with a C8 prep HT column (21.2 mm $\times 150 \mathrm{~mm}$, particle size $5 \mu \mathrm{m}$, Agilent Technologies). Solvent A comprised $0.1 \%$ TFA in deionized water and solvent $\mathrm{B}$ comprised $0.09 \%$ TFA in ACN. The column was equilibrated with $10 \mathrm{CVs}$ of solvent $\mathrm{A}$ at a flow rate of $5 \mathrm{ml} / \mathrm{min}$ and was loaded with the pooled sample at a flow rate of $1 \mathrm{ml} / \mathrm{min}$. After washing with $10 \mathrm{CVs}$ of solvent $\mathrm{A}$ at a flow rate of $5 \mathrm{ml} / \mathrm{min}$, bound proteins were eluted with $10 \mathrm{CVs}$ of solvents $\mathrm{A}$ and $\mathrm{B}$ at a flow rate of $5 \mathrm{ml} / \mathrm{min}$ by application of a linear gradient $(0-100 \%$ solution B). During this process, the solution was monitored at $214 \mathrm{~nm}$ and each peak was collected.

\section{Spectrometry}

The secondary structures of refolded (His) $)_{6} \mathrm{hPrP}(90-230)$ and (His) $)_{6}$ - $\operatorname{PrP}(89-231)$ were determined by CD spectrometry. RecPrP was diluted to $1 \mathrm{mg} / \mathrm{ml}$ in $20 \mathrm{mM}$ sodium acetate (pH5.5). CD spectra of the samples in cells of $1 \mathrm{~mm}$ path length were measured using a Chirascan circular dichroism spectrometer (Applied Photophysics, UK). CD data were collected from 190 to $260 \mathrm{~nm}$ with a $1 \mathrm{~nm}$ bandwidth at $25^{\circ} \mathrm{C}$ and are expressed as the mean residue ellipticity from three scans collected on a sample. $\mathrm{CD}$ results of (His) ${ }_{6}-\mathrm{hPrP}(90-230)$ and $(\mathrm{His})_{6}-\mathrm{mPrP}(89-231)$ were confirmed by at least three independent readings. 


\section{SDS-PAGE and Western Blotting}

Protein samples collected during expression and purification steps were analyzed by SDS-PAGE and stained with Coomassie Brilliant Blue. These samples were also analyzed by western blotting using monoclonal anti-(His) ${ }_{6}$ tag antibody (1:1,000 dilution, Abcam, UK), and anti-PrP antibodies 6D11 (1:30,000 dilution, BioLegend, USA) and 3F4 (1:10,000 dilution, BioLegend). Goat anti-mouse IgG $(\mathrm{H}+\mathrm{L})$ antibody conjugated with horseradish peroxidase (1:5,000 dilution, Thermo Scientific Korea, Korea) was used as the secondary antibody. Using the G:Box Chemi XR5 system and GeneTools software (Syngene, UK), chemiluminescent detection of recPrP was performed with Amersham ECL Prime Western Blotting Detection Reagent (GE Healthcare Bio-Sciences).

\section{Analytical HPLC to Estimate Purity}

To estimate the purity of the recPrPs, samples were analyzed using a Waters HPLC system (USA) equipped with a SKYPAK C8 analytical column $(250 \mathrm{~nm} \times 4.6 \mathrm{~mm}$, particle size $5 \mu \mathrm{m}$, SK Chemicals, Korea). Buffer A comprised $0.1 \%$ TFA in deionized water and buffer B comprised $0.09 \%$ TFA in ACN. The analysis was performed under a linear gradient of $0 \%$ to $80 \%$ buffer $B$ to buffer $A$ at a flow rate of $1 \mathrm{ml} / \mathrm{min}$ for $30 \mathrm{~min}$. Twenty $\mu \mathrm{l}$ of the samples were injected and monitored at $280 \mathrm{~nm}$ by UV detector.

\section{Measurement of Prion Seeding Activity}

PAFA was performed in the presence of misfolded PrP molecules from various human (IRB No: 2016-01-05-R-A) and mouse (IACUC No: 2017-0017A) sources to measure seeding activity. Briefly, the PAFA reaction included $0.2 \mu \mathrm{M}$ recPrP and $2 \mu \mathrm{l}$ of seeds in $200 \mu \mathrm{l}$ reaction buffer (PBS, pH 7.0, 0.2 M guanidine hydrochloride and $10 \mu \mathrm{M}$ ThT) [23]. Seeds were initially prepared by a thousand-fold dilution of prion-infected and -uninfected normal biological matter in PBS and, then, a hundred-fold further diluted in PAFA reactions in a homologous manner. Homogenates of the brains of sporadic CJD patients and normal individuals deposited in the Korea Centers for Disease Control and Prevention (Korea) were used as seeds for (His) ${ }_{6}$-hPrP(90-230) aggregation. Similarly, homogenates of terminally ill prion-infected and normal mice brains, as well as prion-infected ( $\mathrm{ScN} 2 \mathrm{a})$ and uninfected (N2a) neuroblastoma cells, were used as seeds for $(\mathrm{His})_{6}-\mathrm{mPrP}(89-231)$ aggregation. PAFA was performed in 96-Well Black UniPlate microplates (GE Healthcare) by incubating the plates at $37^{\circ} \mathrm{C}$ for $48 \mathrm{~h}$ with shaking at $300 \mathrm{rpm}$. Formation of PrP aggregates was monitored every $5 \mathrm{~min}$ by reading the fluorescence of the ThT bound to amyloids using fluorescence microplate readers equipped with excitation $(444 \mathrm{~nm})$ and emission $(485 \mathrm{~nm})$ filters. With regard to biosafety measures, PAFAs for human samples were performed using a FLUOstar Omega microplate reader (BMG Labtech $\mathrm{GmbH}$, Germany) in the BL-3 laboratory of the Korea Centers for Disease Control and Prevention (Korea). PAFAs for mouse samples were performed using an Infinite M200Pro Multimode Reader (Tecan, Switzerland) in a BL-2 laboratory at Hanyang University (Korea).

\section{Results}

Production of Recombinant Plasmids for Bacterial Expression of (His) ${ }_{6}$-hPrP(90-230) and (His) ${ }_{6}$ - $\mathrm{MPrP}(89-231)$

The $423 \mathrm{bp}$ - and $429 \mathrm{bp}$-long PrP gene fragments encoding the C-terminal globular domain of human and mouse $\operatorname{PrP}^{\mathrm{C}}$, respectively, were PCR-amplified (Fig. S3A) and cloned in pET100/D-TOPO (Fig. S3B). Successful cloning was evidenced by the fact that the sum of the PCR product size ( $\sim 430 \mathrm{bp})$ and the sequence span between NheI and SacI sites $(\sim 130 \mathrm{bp})$ in the vector was comparable to the size of the insert DNA fragments when the recombinant plasmids were digested with the corresponding restriction enzymes. Separately, DNA sequencing of recombinant plasmids confirmed the cloning of gene fragments for the C-terminal globular domain of human and mouse $\operatorname{PrP}^{\mathrm{C}}$.

\section{Expression of (His) $)_{6}-\mathrm{hPrP}(90-230)$ and $(\mathrm{His})_{6}-\mathrm{mPrP}(89-231)$ during Fermentation}

Fermentation to express (His) ${ }_{6}-\mathrm{hPrP}(90-230)$ and (His) ${ }_{6}^{-}$ $\mathrm{mPrP}(89-231)$ was performed for 23 and $25 \mathrm{~h}$, respectively. Protein expression was induced when the $\mathrm{OD}_{600}$ reached 15.6 for (His) ${ }_{6}-\mathrm{hPrP}(90-230)$ and 13.3 for (His) ${ }_{6}-\mathrm{mPrP}(89-$ 231) by adding IPTG to a final concentration of $1 \mathrm{mM}$. Cell culture was continued for an additional $6 \mathrm{~h}$ for (His) ${ }_{6}-$ $h \operatorname{PrP}(90-230)$ and $4 \mathrm{~h}$ for (His) ${ }_{6}-\mathrm{mPrP}(89-231)$. The final $\mathrm{OD}_{600}$ reached 21.3 for (His) ${ }_{6}-\mathrm{hPrP}(90-230)$ and 24.0 for (His) ${ }_{6}-\mathrm{mPrP}(89-231)$ (Fig. 1A and 1B). The wet cell weights obtained were 28.6 for (His) ${ }_{6}-\mathrm{hPrP}(90-230)$ and 46.9 for (His) $)_{6}-\mathrm{mPrP}(89-231)$. Sample aliquots were collected at several time points after raising the temperature to $30^{\circ} \mathrm{C}$ or $37^{\circ} \mathrm{C}$ for (His) ${ }_{6}-\mathrm{hPrP}(90-230)$ and (His) ${ }_{6}-\mathrm{mPrP}(89-231)$, respectively, to determine expression level during the time course of cell culture. SDS-PAGE analysis showed that expression of (His) ${ }_{6}-\mathrm{hPrP}(90-230)$ and (His) ${ }_{6}-\mathrm{mPrP}(89-231)$ was induced after addition of IPTG (Fig. 1C and 1D). The molecular weight of both (His) ${ }_{6}-\mathrm{hPrP}(90-230)$ and (His) ${ }_{6}-$ $\mathrm{mPrP}(89-231)$ was $19 \mathrm{kDa}$.

\section{Expressed Recombinant (His) ${ }_{6}-\mathrm{hPrP}(90-230)$ and (His) ${ }_{6}^{-}$ mPrP(89-231) in Inclusion Bodies}

Inclusion bodies were prepared by separating insoluble protein aggregates from disrupted cells. These aggregates were washed with washing buffer and deionized water. SDS-PAGE analysis showed that (His) ${ }_{6}-\mathrm{hPrP}(90-230)$ and (His) ${ }_{6}-\mathrm{mPrP}(89-231)$ were present in the inclusion bodies, although a number of non-PrP protein species were included at a low level (Fig. 2A and 2B, Lanes 1-5). The purity of 


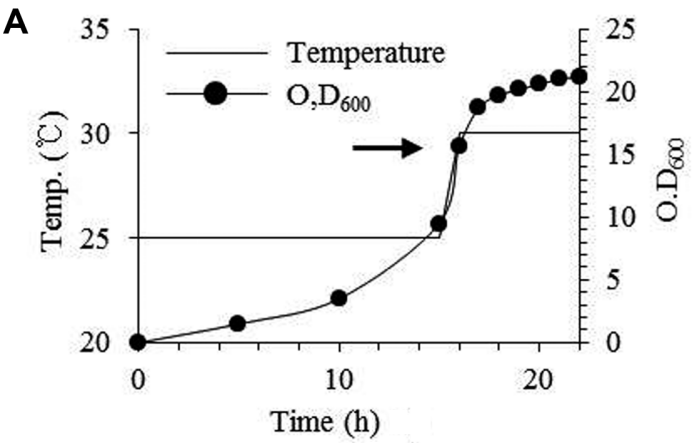

C

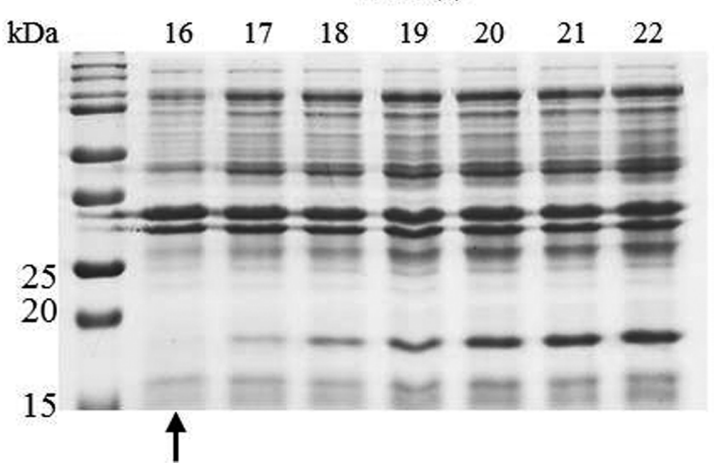

B

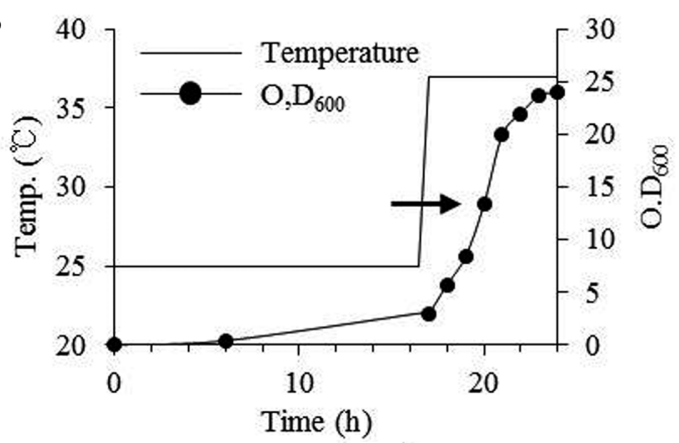

D

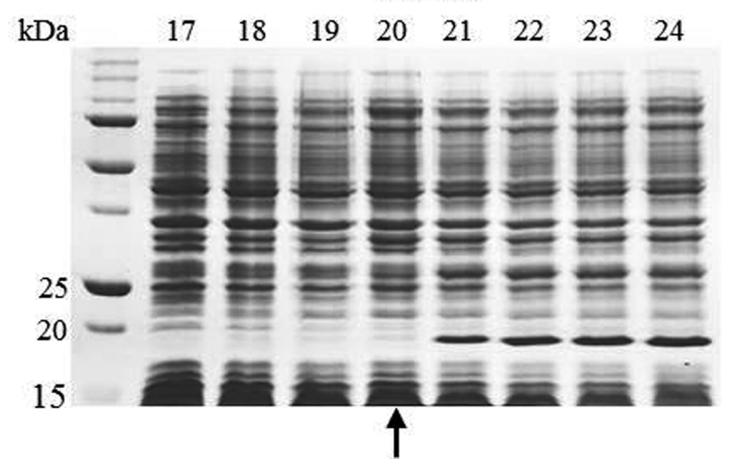

Fig. 1. Cell culture and SDS-PAGE analysis of recPrP expression.

Fermentation and growth curves of (His) $)_{6}-\mathrm{hPrP}(90-230)(\mathbf{A})$, and (His) $)_{6}-\mathrm{mPrP}(89-231)(\mathbf{B})$. The cells for $(\mathrm{His})_{6}-\mathrm{hPrP}(90-230)$ were cultured for $15 \mathrm{~h}$ at $25^{\circ} \mathrm{C}$ and expression was induced with $1 \mathrm{mM}$ IPTG for $6 \mathrm{~h}$ at $30^{\circ} \mathrm{C}$. The cells for (His) ${ }_{6}-\mathrm{mPrP}(89-231)$ were cultured for $16 \mathrm{~h}$ at $25^{\circ} \mathrm{C}$ and expression was induced with $1 \mathrm{mM}$ IPTG for $4 \mathrm{~h}$ at $30^{\circ} \mathrm{C}$. SDS-PAGE analysis of expressed (His) $)_{6} \mathrm{hPrP}(90-230)(\mathrm{C})$ and $(\mathrm{His})_{6}-\mathrm{mPrP}(89-231)(\mathrm{D})$ according to indicated culture time. Arrows indicate the addition of IPTG.

recPrPs in the inclusion bodies increased progressively during repeated washing.

Purification of (His) ${ }_{6}$-hPrP(90-230) and (His) ${ }_{6}-\mathrm{mPrP}(89-231)$ by Sequential Chromatography

RecPrP was first purified by nickel affinity chromatography.
Proteins bound to the resin were washed with washing buffer containing $100 \mathrm{mM}$ imidazole. The fusion protein was eluted with elution buffer containing $1 \mathrm{M}$ imidazole and the fractions were collected. Analysis of pooled fractions by SDS-PAGE demonstrated that highly pure recPrPs were enriched by IMAC (Fig. 2A and 2B, Lane 6).
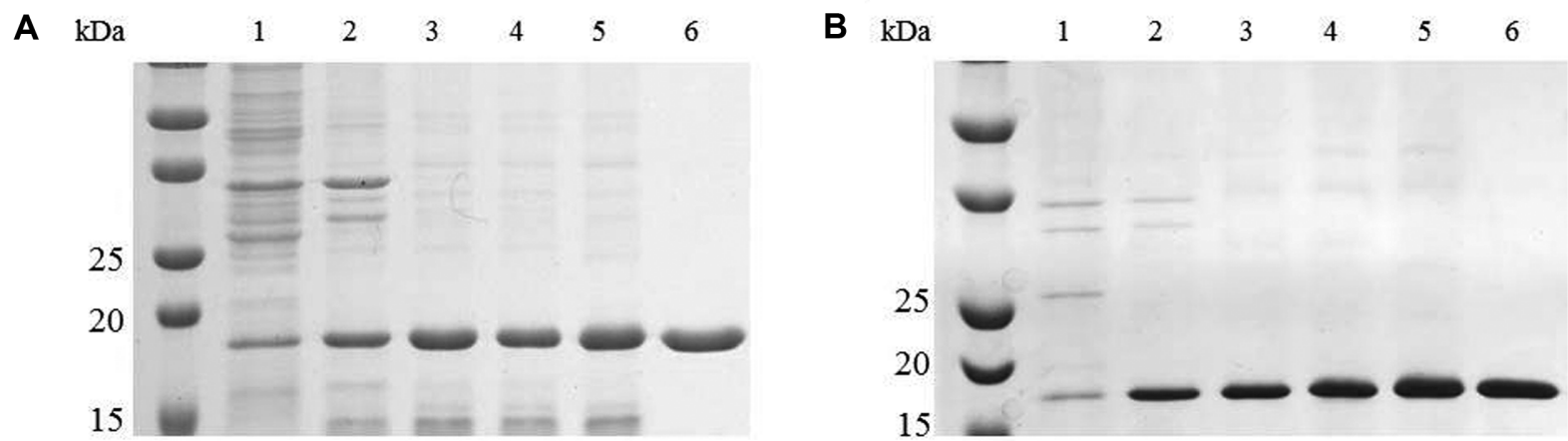

Fig. 2. SDS-PAGE analysis of recPrPs during inclusion body washing and IMAC.

(A) (His) ${ }_{6}$-hPrP(90-230). (B) (His) ${ }_{6}-\mathrm{mPrP}(89-231)$. Lane 1: Total cell lysate of induced recPrPs, Lane 2: Pellet, Lane 3: The first wash of inclusion body, Lane 4: The second wash of inclusion body, Lane 5: Solubilized inclusion body, Lane 6: Pooled fraction containing recPrPs from IMAC. 
A
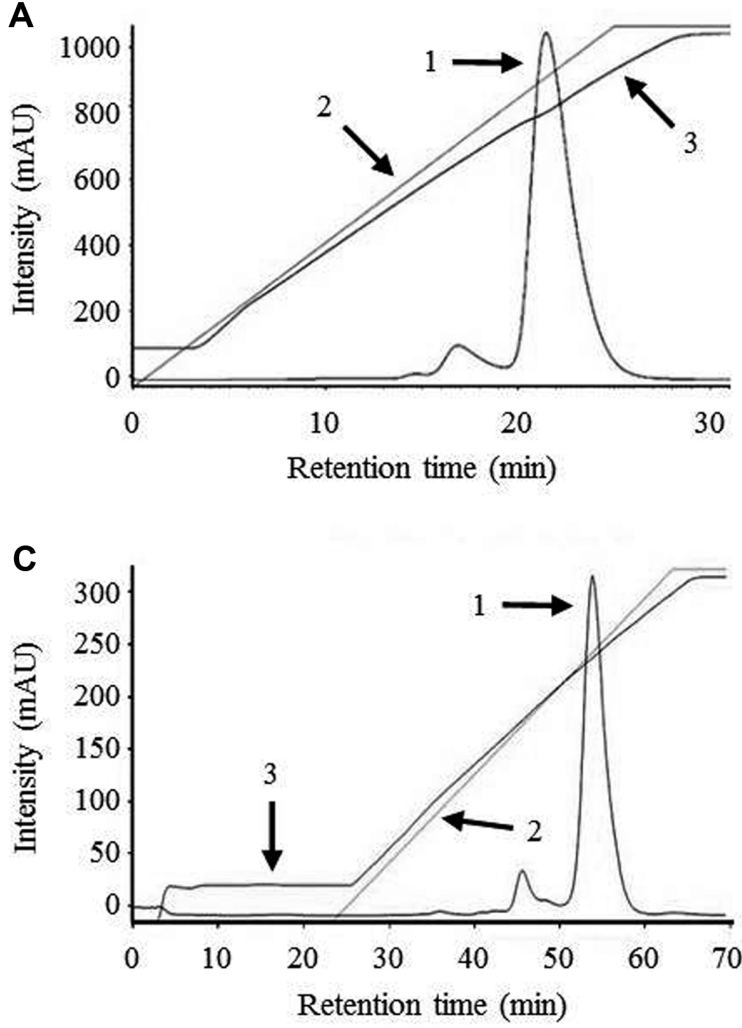

B

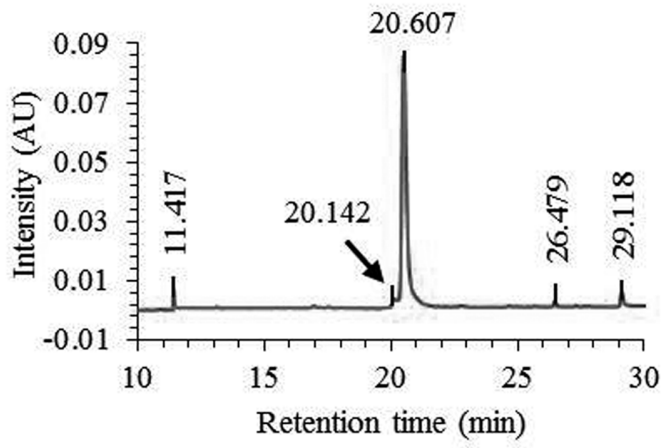

D

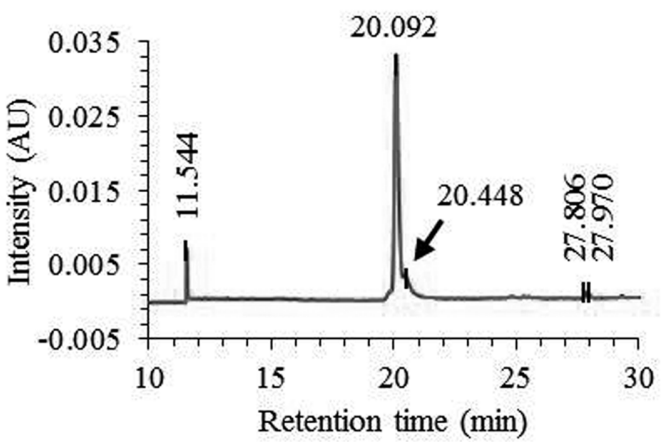

Fig. 3. Purification of recPrPs using cation-exchange chromatography. Cation-exchange chromatograms of (His) ${ }_{6}-\mathrm{hPrP}(90-230)$ (A) and (His) $)_{6}-\mathrm{mPrP}(89-231)$ (C) with a HiTrap Sp column. Arrows indicate recPrPs (1), percentage of buffer B (\%) (2), and conductivity (3). HPLC chromatogram of (His) $)_{6} \mathrm{hPrP}(90-230)$ (B) and (His) ${ }_{6}-\mathrm{mPrP}(89-231)(\mathbf{D})$.

To improve the purity of recPrPs, pooled IMAC elution fractions were subjected to cation-exchange chromatography. During elution of loaded HiTrap SP columns with a linear gradient, ranging from 0 to $1 \mathrm{M} \mathrm{NaCl}$, the major peak of recPrPs was detected at around $0.8-1 \mathrm{M} \mathrm{NaCl}$ for $(\mathrm{His})_{6^{-}}$ $\mathrm{hPrP}(90-230)$ and $0.75-0.9 \mathrm{M} \mathrm{NaCl}$ for (His) ${ }_{6}-\mathrm{mPrP}(89-231)$ (Fig. 3A and 3C). Based on the HPLC chromatogram obtained using the Protein \& Peptide C8 analytical column, the purity of (His) $)_{6} \mathrm{hPrP}(90-230)$ was $91.5 \%$ and that of (His) ${ }_{6}$ - $\mathrm{mPrP}(89-231$ ) was $91.4 \%$ (Fig. 3B and 3D).

As a final chromatography step to increase the purity of recPrPs, the pooled PrP solution prepared from cation exchange chromatography was loaded on a reverse-phase chromatography column. Elution was accomplished with a linear gradient containing $0 \%$ to $70 \%$ ACN. The PrepHPLC chromatogram of the C8 prep HT column showed that the main peak of recPrPs was found in the range of $43-45 \% \mathrm{ACN}$ for (His) $)_{6} \mathrm{hPrP}(90-230)$ and $38-42 \% \mathrm{ACN}$ for (His) $)_{6}-\mathrm{mPrP}(89-231)$ (Fig. 4A and 4C). SDS-PAGE of recPrPs found in the main peak showed pure recPrPs as a single band in the gel with no other impure protein bands (Fig. 4B and $4 \mathrm{D}$ ).

RecPrP production from cells fermented to a high density followed by multiple chromatography purification steps yielded 72 and $60 \mathrm{mg}$ per liter for (His) ${ }_{6}-\mathrm{hPrP}(90-230)$ and (His) ${ }_{6}-\mathrm{mPrP}(89-231)$, respectively.

\section{Confirmation of Purified recPrPs by Immunoblotting}

To confirm the identity of the purified recPrPs, western blotting using different antibodies was performed. Reactivity of both (His) $)_{6}-\mathrm{hPrP}(90-230)$ and (His) ${ }_{6}-\mathrm{mPrP}(89-231)$ with anti-(His) ${ }_{6}$ antibody confirmed that the recPrPs were expressed as His-tagged fusion proteins (Fig. S4A). Detection of both (His) $)_{6}-\mathrm{hPrP}(90-230)$ and $(\mathrm{His})_{6}-\mathrm{mPrP}(89-231)$ by anti-PrP 6D11 antibody, but failure to detect (His) ${ }_{6}{ }^{-}$ $\mathrm{mPrP}(89-231)$ using the anti-PrP 3F4 antibody, confirmed that the purified recombinant proteins represented their corresponding PrPs (Fig. S4B and S4C), because the epitope of 3F4 is available for antibody binding in $\mathrm{hPrP}$, but not $\mathrm{mPrP}$ [49]. 
A

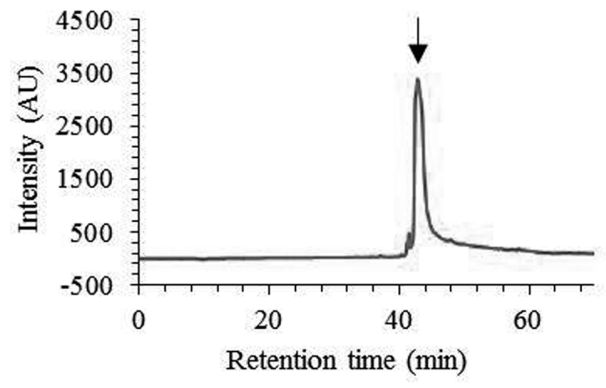

C

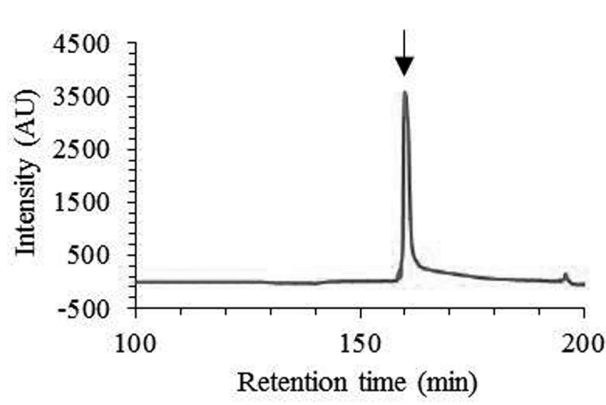

Fig. 4. Preparative HPLC chromatography and SDS-PAGE analysis of purified recPrPs.

Preparative HPLC chromatograms of (His) ${ }_{6}-\mathrm{hPrP}(90-230)$ (A) and (His) ${ }_{6}-\mathrm{mPrP}(89-231)$ (C) with C8 prep HT column. SDS-PAGE analysis of pooled fractions containing (His) ${ }_{6}-\mathrm{hPrP}(90-230)(\mathbf{B})$ and (His) ${ }_{6}-\mathrm{mPrP}(89-231)$ (D).

Secondary Structure of Refolded (His) ${ }_{6}-\mathrm{hPrP}(90-230)$ and (His) ${ }_{6}$-mPrP(89-231)

To assess whether refolding performed during purification allowed the recPrPs to retain a conformation similar to that of native $\operatorname{PrP}^{\mathrm{C}}$, the secondary structures of (His) ${ }_{6}-\mathrm{hPrP}(90-$ 230) and (His) ${ }_{6}-\mathrm{mPrP}(89-231)$ were analyzed by $\mathrm{CD}$ spectrometry. CD spectra of both recPrPs demonstrated a positive maximum at $193 \mathrm{~nm}$ and double negative maxima at 208 and $220 \mathrm{~nm}$ (Fig. S5). These results indicated that both (His) $)_{6}-\mathrm{hPrP}(90-230)$ and (His) $)_{6}-\mathrm{mPrP}(89-231)$ adopted the typical $\alpha$-helix-rich conformation.

\section{Purity of Purified (His) ${ }_{6}-\mathrm{hPrP}(90-230)$ and (His) ${ }_{6}-\mathrm{mPrP}(89-$} 231)

The purity of the final (His) $)_{6}-\mathrm{hPrP}(90-230)$ and (His) ${ }_{6}-$ $\mathrm{mPrP}(89-231)$ products was determined by analytical HPLC with a Protein \& Peptide C8 analytical column. The HPLC chromatogram showed a single peak with a retention time at $\sim 20 \mathrm{~min}$ for both recPrPs (Fig. S6). Calculation of the integrated area under the peak indicated that the purity of (His) ${ }_{6}$-hPrP(90-230) was $95.7 \%$ while that of (His) $)_{6}-\mathrm{mPrP}(89-$ 231) was $95.8 \%$.

\section{Utility of Produced recPrPs as Substrates to Measure the Seeding Activity of Prions}

To estimate whether recPrPs generated by the method described in the present study are suitable to measure the seeding activity of prions, (His) ${ }_{6}-\mathrm{hPrP}(90-230)$ and (His) ${ }_{6}-$ $\mathrm{mPrP}(89-231)$ were tested as substrates in PAFA. In the presence of seeds prepared from a CJD brain, the length of the lag phase for aggregation of misfolded (His) ${ }_{6}-\mathrm{hPrP}(90-$ 230) ( $17.5 \mathrm{~h})$ was reduced by $4.5-9 \mathrm{~h}$ compared to the lag phase obtained in the absence of seeds $(\sim 26.5 \mathrm{~h})$ or in the presence of seeds prepared from normal brains $(\sim 22 \mathrm{~h})$ (Fig. 5A). Similarly, aggregation of misfolded (His) ${ }_{6}-\mathrm{mPrP}(89-$ 231) was also accelerated $8-9 \mathrm{~h}$ and $6-9 \mathrm{~h}$ by seeds prepared from prion-infected cells and mouse brains, respectively
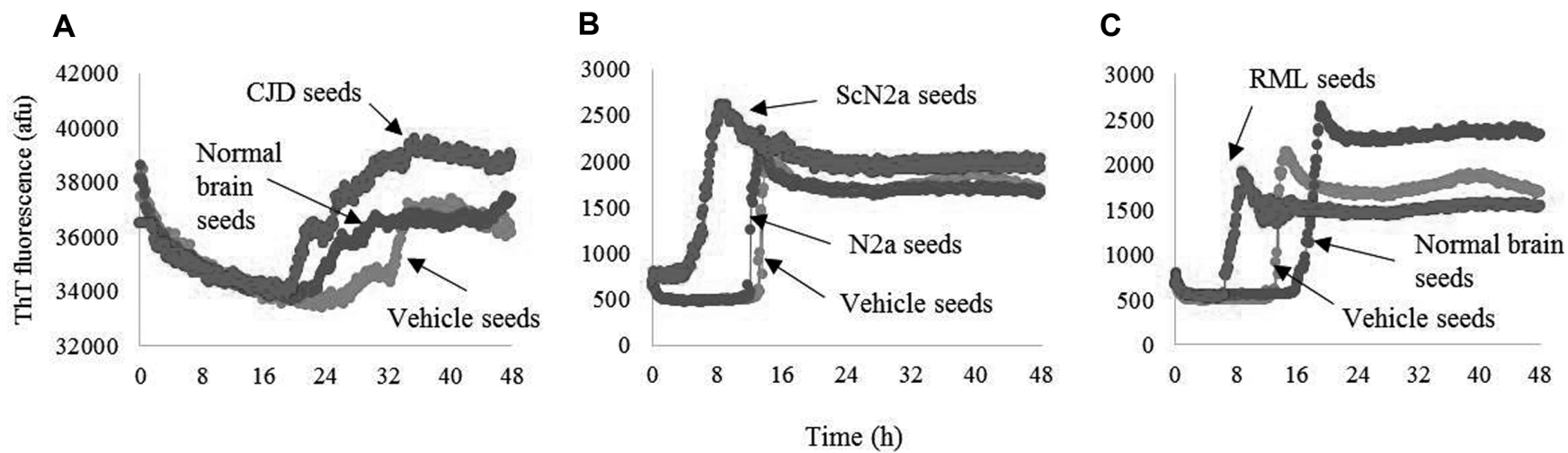

Fig. 5. Application of purified recPrPs to assays to measure prion seeding activity.

PAFA using (His) $)_{6}$ hPrP(90-230) was performed with CJD/normal brain seeds (A). PAFA using (His) ${ }_{6}$-mPrP(89-231) was performed with ScN2a/ N2a (B) and prion-infected/uninfected brain seeds (C). 
(Fig. 5B and 5C). Although irrelevant to the measurement of seeding activity, the amplitudes of fluorescence measured in PAFA with or without misfolded seeds varied (Fig. 5). These results demonstrate that both (His) ${ }_{6}-\mathrm{hPrP}(90-230)$ and (His) ${ }_{6}-\mathrm{mPrP}(89-231)$ generated in this study can be reliably used in assays to evaluate the seeding activity of prions.

\section{Discussion}

The current study reports the technical establishment of a method to mass-produce highly pure recPrP by using high cell-density fermentation and three sequential chromatographic purification procedures. This study simultaneously achieved two essential goals of recPrP production, a high purity and a large quantity. Supply of highly pure recPrP in large quantity is important for prion detection using the assay platform of in vitro PrP aggregation [50]. Thus, development of a strategy to produce high-quality recPrP is advantageous for dependable prion detection tests, which rely on a large quantity of substrate.

E. coli is the most widely used host cell to produce recombinant proteins because of its unparalleled fast growth kinetics [51], easy transformation with exogenous plasmid DNA [52], and low culture costs. High cell-density fermentation can easily be performed and produces a large microbial cell mass [53]. However, during this process, cells encounter disadvantageous conditions such as exhaustion of dissolved oxygen, nutrient depletion, changing $\mathrm{pH}$, elevated osmotic pressure, and byproduct formation. To solve these problems, feeding strategies such as DO-stat and $\mathrm{pH}$-stat have been adopted in fed-batch fermentation [54]. In this study, the established procedure to produce recPrPs employed fed-batch, high cell-density fermentation using pH-stat. Thus, a large cell mass could be obtained and purification was initiated with a copious amount of initial starting material, which resulted in production of recPrP in a large quantity. In fact, comparison of recPrP production from cells fermented to a high density followed by multiple chromatography purification steps to that from conventional liquid culture with a single affinity chromatography purification step indicates that recPrP production based on the former described in this study is more efficient than that by the latter described elsewhere $[8,23]$. In the case of (His) ${ }_{6}-\mathrm{mPrP}(89-231)$ production, the yield increased $\sim 30$-fold. For an identical volume of cell culture, the final $\mathrm{OD}_{600}$ and wet cell weight were greater by more than 20-fold.

Purity is a crucial factor for experiments that use recPrPs.
Although IMAC effectively enriches His-tagged recPrPs, a certain level of non-recPrP material is believed to be included in the eluates. To exclude impurities, two additional purification steps, cation exchange and reverse-phase chromatography, were used in this study. Indeed, analyses of analytical HPLC chromatograms demonstrated that the purity of recPrP purified by cation exchange chromatography was $91.5 \%$ for $h \operatorname{PrP}(90-230)$ and $91.4 \%$ for $m \operatorname{PrP}(89-231)$, and that the purity of recPrP purified by reverse-phase chromatography was $95.7 \%$ for $h \operatorname{PrP}(90-230)$ and $95.8 \%$ for $\mathrm{mPrP}(89-231)$. These data indicate that sequential application of different chromatography steps successfully increased the purity of recPrP to a high level. Usually, purification of recPrP is achieved by one- or two-step chromatography [8, $25,30,34,35,43$ ]. RecPrP produced in our study is of high quality and will be a useful resource for studies that require recPrP. In particular, use of recPrP substrates free of other macromolecules is critical for seeding assays. Some macromolecules, such as lipids and nucleic acids, have been shown to assist in PrP conversion as cofactors [7, 55, 56]. Exclusion of such contaminants helps establish precise assays.

One of the unavoidable drawbacks involved in refolding of recPrP prepared using the conventional method is the considerable loss of protein by precipitation. This decreases the amount of recPrP that can be obtained as a final product, despite successful purification. It is common to lose recPrP when the protein is purified first and refolded afterwards. The protocol used in the current study includes repeated denaturation and renaturation; refolding of denatured recPrP in the presence of low concentrations of denaturant and reducing agent, temporal denaturation of refolded recPrP with the high concentration of denaturant in the absence of reducing agent during ion exchange chromatography, and then, final renaturation at the end of purification. The order of processes in this study explains how the massive loss of recPrP could be prevented, improving the yield per cell mass.

Highly pure recPrPs mass-produced in this study properly served as substrates in PAFA to measure seeding activity, the indication of aggregation of which initiation is accelerated by the presence of misfolded PrP isoforms. However, the correlation between recPrPs used in PAFA and the level of fluorescence which represents the degree of aggregation in the current study was not established. Traditionally, the level of misfolded conformer in seeds is determined by measuring the ability to initiate aggregation, which is proportional to the abbreviated lag phase of PrP aggregation, but not by measuring the level of aggregated PrP. Regardless, 
whether the quality of substrates in PAFA influences a high-degree generation of PrP aggregates under a certain seeding condition would be interesting to investigate.

In conclusion, we expressed and purified large quantities of highly pure recPrPs using fed-batch fermentation and sequential chromatography steps. The recPrPs generated showed conformational similarity to native $\operatorname{PrP}^{\mathrm{C}}$ and supported PrP aggregation, one of the major events that characterizes prion diseases. Establishment of such a procedure can help address the issues associated with the production of large quantities of highly pure recPrP.

\section{Acknowledgment}

The authors thank Geun-Hye Ki and Trang H.T. Trinh for technical and Jae-yeon Kim for editorial assistance. This work was supported by the Research Program funded by the Korea Centers for Disease Control and Prevention (2016ER520200) and by grants from the Korea Health Technology R\&D Project through the Korea Health Industry Development Institute (KHIDI) funded by the Ministry of Health and Welfare, Republic of Korea (HI16C1085).

\section{Conflict of Interest}

The authors have no financial conflicts of interest to declare.

\section{Abbreviations}

$\operatorname{PrP}^{\mathrm{C}}$, cellular prion protein; $\mathrm{PrP}^{\mathrm{Sc}}$, scrapie prion protein; CJD, Creutzfeldt-Jakob disease; LB, Luria-Bertani; $\mathbf{O D}_{600}$, optical density at $600 \mathrm{~nm}$; IPTG, isopropyl $\beta$-D-1thiogalactopyranoside; IMAC, Immobilized metal affinity chromatography; CVs, column volumes; Prep-HPLC, Preparative high-performance liquid chromatography; TFA, trifluoroacetic acid; ACN, acetonitrile; CD, circular dichroism; SDS-PAGE, sodium dodecyl sulfate-polyacrylamide gel electrophoresis; PBS, phosphate buffered saline; ThT, thioflavine $\mathrm{T}$

\section{References}

1. Prusiner SB. 1998. Prions. Proc. Natl. Acad. Sci. USA 95: 13363-13383.

2. Pan K-M, Baldwin M, Nguyen J, Gasset M, Serban A, Groth D, et al. 1993. Conversion of a-helices into b-sheets features in the formation of the scrapie prion proteins. Proc. Natl. Acad. Sci. USA 90: 10962-10966.
3. Cohen FE, Prusiner SB. 1998. Pathologic conformations of prion proteins. Annu. Rev. Biochem. 67: 793-819.

4. Caughey B, Baron GS, Chesebro B, Jeffrey M. 2009. Getting a grip on prions: oligomers, amyloids, and pathological membrane interactions. Annu. Rev. Biochem. 78: 177-204.

5. Prusiner SB. 1982. Novel proteinaceous infectious particles cause scrapie. Science 216: 136-144.

6. Legname G, Baskakov IV, Nguyen H-OB, Riesner D, Cohen FE, DeArmond SJ, et al. 2004. Synthetic mammalian prions. Science 305: 673-676.

7. Wang F, Wang X, Yuan C-G, Ma J. 2010. Generating a prion with bacterially expressed recombinant prion protein. Science 327: 1132-1135.

8. Shin W, Lee B, Hong S, Ryou C, Kwon M. 2008. Cloning and expression of a prion protein $(\mathrm{PrP})$ gene from Korean bovine (Bos taurus coreanae) and production of rabbit antibovine PrP antibody. Biotechnol. Lett. 30: 1705-1711.

9. Kim C-L, Umetani A, Matsui T, Ishiguro N, Shinagawa M, Horiuchi M. 2004. Antigenic characterization of an abnormal isoform of prion protein using a new diverse panel of monoclonal antibodies. Virology 320: 40-51.

10. Korth C, Streit P, Oesch B. 1999. Monoclonal antibodies specific for the native, disease-associated isoform of the prion protein. Methods Enzymol. 309: 106-122.

11. White AR, Enever P, Tayebi M, Mushens R, Linehan J, Brandner S, et al. 2003. Monoclonal antibodies inhibit prion replication and delay the development of prion disease. Nature 422: 80-83.

12. Andrievskaia $\mathrm{O}, \mathrm{McRae} H$, Elmgren $C$, Huang $H$, Balachandran A, Nielsen K. 2006. Generation of Antibodies against bovine recombinant prion protein in various strains of mice. Clin. Vaccine Immunol. 13: 98-105.

13. Stanker LH, Serban AV, Cleveland E, Hnasko R, Lemus A, Safar J, et al. 2010. Conformation-dependent high-affinity mAbs to prion proteins. J. Immunol. 185: 729-737.

14. Kang H-E, Weng CC, Saijo E, Saylor V, Bian J, Kim S, et al. 2012. Characterization of conformation-dependent prion protein epitopes. J. Biol. Chem. 287: 37219-37232.

15. Groveman BR, Dolan MA, Taubner LM, Kraus A, Wickner RB, Caughey B. 2014. Parallel in-register intermolecular $\beta$-Sheet architectures for prion-seeded prion protein (PrP) amyloids. J. Biol. Chem. 289: 24129-24142.

16. Damberger FF, Christen B, Pérez DR, Hornemann S, Wüthrich K. 2011. Cellular prion protein conformation and function. Proc. Natl. Acad. Sci. USA 108: 17308-17313.

17. Christen B, Hornemann S, Damberger FF, Wüthrich K. 2009. Prion protein NMR structure from tammar wallaby (Macropus eugenii) shows that the b2-a2 loop is modulated by long-range sequence effects. J. Mol. Biol. 389: 833-878.

18. Tycko R, Savtchenko R, Ostapchenko VG, Makarava N, Baskakov IV. 2010. The $\alpha$-helical C-terminal domain of fulllength recombinant $\operatorname{PrP}$ converts to an in-register parallel $\beta$-sheet structure in PrP fibrils: Evidence from solid state 
NMR. Biochemistry 49: 9488-9497.

19. Wille H, Bian W, McDonald M, Kendall A, Colby DW, Bloch L, et al. 2009. Natural and synthetic prion structure from X-ray fiber diffraction. Proc. Natl. Acad. Sci. USA 106: $16990-16995$.

20. Lee S, Antony L, Hartmann R, Knaus KJ, Surewicz K, Surewicz WK, et al. 2010. Conformational diversity in prion protein variants influences intermolecular $\beta$-sheet formation. EMBO J. 29: 251-262.

21. Wan W, Wille H, Stöhr J, Kendall A, Bian W, McDonald M, et al. 2015. Structural studies of truncated forms of the prion protein PrP. Biophys. J. 108: 1548-1554.

22. Colby DW, Zhang Q, Wang S, Groth D, Legname G, Riesner D, et al. 2007. Prion detection by an amyloid seeding assay. Proc. Natl. Acad. Sci. USA 104: 20914-20919.

23. Kim S-G, Lee H-M, Ryou C. 2014. Parameters that affect macromolecular self-assembly of prion protein. Protein J. 33: 243-252.

24. Atarashi R, Moore RA, Sim VL, Hughson AG, Dorward DW, Onwubiko HA, et al. 2007. Ultrasensitive detection of scrapie prion protein using seeded conversion of recombinant prion protein. Nat. Methods 4: 645-650.

25. Corsaro A, Thellung S, Russo C, Villa V, Arena S, D'Adamo MC, et al. 2002. Expression in E. coli and purification of recombinant fragments of wild type and mutant human prion protein. Neurochem. Intl. 41: 55-63.

26. Makarava N, Baskakov IV. 2012. Purification and fibrillation of full-length recombinant PrP. Methods Mol. Biol. 849: 33-52.

27. Makarava N, Baskakov IV. 2008. Expression and purification of full-length recombinant $\operatorname{Pr} P$ of high purity, pp. 131-143. In Hill AF (ed.), Prion Protein Protocols, Ed. Humana Press, Totowa, NJ

28. Zahn R, von Schroetter C, Wüthrich K. 1997. Human prion proteins expressed in Escherichia coli and purified by highaffinity column refolding. FEBS Lett. 417: 400-404.

29. Marbach J, Zentis P, Ellinger P, Müller H, Birkmann E. 2013. Expression and characterisation of fully posttranslationally modified cellular prion protein in Pichia pastoris. Biol. Chem. 394: 1475-1483.

30. Sakudo A, Hamaishi M, Hosokawa-Kanai T, Tuchiya K, Nishimura T, Saeki K, et al. 2003. Absence of superoxide dismutase activity in a soluble cellular isoform of prion protein produced by baculovirus expression system. Biochem. Biophys. Res. Commun. 307: 678-683.

31. Faburay B, Tark D, Kanthasamy AG, Richt JA. 2014. In vitro amplification of scrapie and chronic wasting disease $\operatorname{PrP}($ res) using baculovirus-expressed recombinant $\operatorname{PrP}$ as substrate. Prion. 8: 393-403.

32. Chu NK, Becker CFW. 2013. Recombinant expression of soluble murine prion protein for C-terminal modification. FEBS Lett. 587: 430-435.

33. Arii Y, Oshiro S, Wada K, Fukuoka S-I. 2011. Production of a recombinant full-length prion protein in a soluble form without refolding or detergents. Biosci. Biotechnol. Biochem. 75: 1181-1183.

34. Völkel D, Blankenfeldt W, Schomburg D. 1998. Large-scale production, purification and refolding of the full-length cellular prion protein from Syrian golden hamster in Escherichia coli using the glutathione S-transferase-fusion system. Eur. J. Biochem. 251: 462-471.

35. Mehlhorn I, Groth D, Stockel J, Moffat B, Reilly D, Yansura D, et al. 1996. High-level expression and characterization of a purified 142-residue polypeptide of the prion protein. Biochemistry 35: 5528-5537.

36. Borchelt DR, Rogers M, Stahl N, Telling G, Prusiner SB. 1993. Release of the cellular prion protein from cultured cells after loss of its glycoinositol phospholipid anchor. Glycobiology 3: 319-329.

37. Gorodinsky A, Harris DA. 1995. Glycolipid-anchored proteins in neuroblastoma cells form detergent-resistant complexes without caveolin. J. Cell Biol. 129: 619-627.

38. Dan H, Balachandran A, Lin M. 2009. A pair of ligationindependent Escherichia coli expression vectors for rapid addition of a polyhistidine affinity tag to the $\mathrm{N}$ - or Ctermini of recombinant proteins. J. Biomol. Tech. 20: 241-248.

39. Macedo B, Millen TA, Braga CACA, Gomes MPB, Ferreira PS, Kraineva J, et al. 2012. Nonspecific prion protein-nucleic acid interactions lead to different aggregates and cytotoxic species. Biochemistry 51: 5402-5413.

40. Vrlinic T, Debarnot D, Legeay G, Coudreuse A, El Moualij B, Zorzi $\mathrm{W}$, et al. 2012. Are the interactions between recombinant prion proteins and polymeric surfaces related to the hydrophilic/hydrophobic balance? Macromol. Biosci. 12: 830839.

41. Zobeley E, Flechsig E, Cozzio A, Enari M, Weissmann C. 1999. Infectivity of scrapie prions bound to a stainless steel surface. Mol. Med. 5: 240-243.

42. Enari M, Flechsig E, Weissmann C. 2001. Scrapie prion protein accumulation by scrapie-infected neuroblastoma cells abrogated by exposure to a prion protein antibody. Proc. Natl. Acad. Sci. USA 98: 9295-9299.

43. Arii Y, Yamaguchi H, Fukuoka S-I. 2007. Production of a soluble recombinant prion protein fused to blue fluorescent protein without refolding or detergents in Escherichia coli cells. Biosci. Biotechnol. Biochem. 71: 2511-2514.

44. Zhang F-P, Zhang J, Zhou W, Zhang B-Y, Hung T, Dong X-P. 2002. Expression of PrPC as HIS-fusion form in a baculovirus system and conversion of expressed PrP-sen to PrP-res in a cell-free system. Virus Res. 87: 145-153.

45. Zhang H, Stockel J, Mehlhorn I, Groth D, Baldwin MA, Prusiner SB, et al. 1997. Physical studies of conformational plasticity in a recombinant prion protein. Biochemistry. 36: 3543-3553.

46. Hornemann S, Korth C, Oesch B, Riek R, Wide G, Wüthrich K, et al. 1997. Recombinant full-length murine prion protein, $\mathrm{mPrP}(23-231)$ : purification and spectroscopic characterization. 
FEBS Lett. 413: 277-281.

47. Lu BY, Beck PJ, Chang JY. 2001. Oxidative folding of murine prion $\mathrm{mPrP}(23-231)$. Eur. J. Biochem. 268: 3767-3773.

48. Vrentas CE, Onstot S, Nicholson EM. 2012. A comparative analysis of rapid methods for purification and refolding of recombinant bovine prion protein. Protein. Expr. Purif. 82: 380-388.

49. Kascsak RJ, Rubenstein R, Merz PA, Tonna-DeMasi M, Fersko R, Carp RI, et al. 1987. Mouse polyclonal and monoclonal antibody to scrapie-associated fibril proteins. J. Virol. 61: 3688-3693.

50. Kang H-E, Mo Y, Abd Rahim R, Lee H-M, Ryou C. 2017. Prion diagnosis: application of real-time quaking-induced conversion. BioMed. Res. Intl. 2017: 5413936

51. Mullner S, Hoyle V. 1992. A method for directly determining intact recombinant insulin fusion proteins in crude fermentation extracts. Anal. Biochem. 202: 394-399.
52. Clark EDB. 1998. Refolding of recombinant proteins. Curr. Opin. Biotechnol. 9: 157-163.

53. Cowley DJ, Mackin RB. 1997. Expression, purification and characterization of recombinant human proinsulin. FEBS Lett. 402: 124-130.

54. Sun J. 2012. Rapid strain evaluation using dynamic DO-stat fed-batch fermentation under scale-down conditions. Methods Mol. Biol. 834: 233-244.

55. Deleault NR, Geoghegan JC, Nishina K, Kascsak R, Williamson RA, Supattapone S. 2005. Protease-resistant prion protein amplification reconstituted with partially purified substrates and synthetic polyanions. J. Biol. Chem. 280: 26873-26879.

56. Deleault NR, Lucassen RW, Supattapone S. 2003. RNA molecules stimulate prion protein conversion. Nature 425: 717-720. 